\title{
HÁBITOS DE LEITURA DURANTE A PANDEMIA: UMA ANÁLISE SOBRE AS AÇÕES E AS DIFICULDADES ENFRENTADAS POR UMA ESCOLA PÚBLICA ESTADUAL E SEUS PROFESSORES
}

\author{
Clarê Mochinski ${ }^{1}$
}

RESUMO: A Educação brasileira passa por mudanças significativas desde o início da pandemia causada pelo COVID-i9 em 2020. Pensando nisso, o presente estudo proporciona meios para reflexões sobre a importância da escola e dos professores no incentivo à leitura e suas dificuldades em estimular a rotina de ler em tempos de pandemia. Para isso, traz como objetivo geral identificar as principais ações e dificuldades enfrentadas pela escola e pelos professores, a respeito do desempenho da leitura em tempo de pandemia. Já os objetivos específicos pretendem conhecer os problemas de leitura que se modificam na ausência da aula presencial, entender como escola e professores estão conduzindo o processo de incentivo à leitura, compreender o cenário educacional relacionado ao incentivo à leitura de uma escola no município de Pimenta Bueno - RO frente à pandemia e as mudanças na atuação educativa. Para isso, a metodologia usada na elaboração do estudo foi a pesquisa bibliográfica para obter informações sobre o assunto, e a pesquisa de campo por meio de questionário com perguntas abertas, o qual foi respondido através do Google Form, pela coordenação pedagógica da escola e pelos professores de Língua Portuguesa. A pesquisa justifica-se por ajudar a contextualizar informações relevantes sobre o incentivo escolar relativo às práticas de leitura em tempos de pandemia. Nessa circunstância, a investigação mostra que as práxis da escola e dos professores, se desenvolve na apresentação de uma nova organização de atividades escolar que passou a funcionar com aulas remotas, modificando o sistema de ensino e incentivo dos alunos com acesso a novas tecnologias e meios de comunicação, o que interferiu diretamente na maneira de como se promover a leitura.

Palavras chaves: Incentivo. Leitura Pandemia.

\section{INTRODUÇÃO}

Com a pandemia do novo coronavírus (Covid-19) a partir de 2020, escolas suspenderam as aulas presenciais e passaram a buscar formas alternativas de manter $o$ processo de ensino-aprendizagem durante a quarentena: usam principalmente aplicativos e plataformas on-line. A Educação precisou desenvolver características que

IE-mail: clareoliveira@hotmail.com 
concedem sua adaptação em contextos sociais diferentes, isso acontece porque o ser humano é um ser social e aprende a conviver a partir do momento que vivencia uma situação interagindo com o outro. Essa aproximação se dá através da necessidade de comunicação, e a leitura torna-se uma das principais formas de sociabilização. Leitura é fonte inesgotável de prazer e entretenimento é uma das melhores formas de viajar sem sair de casa (Dias; Quadros, 2015). Os hábitos de leituras desenvolvidos durante a formação escolar, somam um grau relevante de significados na vida do sujeito, sendo um elemento de expressão que representa o todo e as particularidades de uma determinada realidade, a vida em sua forma mais simples e peculiar, por isso deve ser estimulada dentro e fora do espaço escolar.

Nesse tempo de pandemia, a leitura é algo importante na vida do ser humano pois, ler estimula a criatividade, trabalha a imaginação, exercita a memória, contribui com o crescimento do vocabulário, evita stress distraindo as pessoas dos acontecimentos diários estimulando a ter novos pensamentos para enfrentar o período de pandemia. Sendo assim, o objetivo geral do estudo buscou identificar as principais ações e dificuldades enfrentadas pela escola e pelos professores, a respeito do desempenho em tempos de pandemia.

Já os objetivos específicos pretenderam conhecer os problemas de leitura que se modificam na ausência da aula presencial e como a escola está conduzindo o processo de incentivo à leitura, compreender as ações realizadas pelos professores em busca de promover a leitura, identificar o cenário educacional relacionado ao incentivo da leitura de uma escola no município de Pimenta Bueno - RO frente à pandemia e as mudanças nas ações educativas.

A questão norteadora do estudo se configura como uma das principais indagações do estudo: como a escola e os professores estimulam o hábito de ler em tempos de pandemia? Sabe-se que a leitura deveria ser uma prática na vida de todos os sujeitos, de alguma forma sempre fomos envolvidos por ela.

Conhecer como a escola e os professores têm trabalhado o conteúdo com ênfase no estímulo do hábito de ler é importante e necessário. Por isso, foi realizada uma pesquisa de campo e bibliográfica, tendo o questionário, instrumento principal da investigação, elaborado com perguntas abertas, enviado à escola e aos professores com o 
propósito de entender como estão sendo desenvolvidas as ações realizadas com as mudanças no ensino.

\section{REFERENCIAL TEÓRICO}

O ensino escolar no nosso país tem passado por mudanças frequentes, porém a leitura é uma atividade essencial à vida dos estudantes todavia, a escola precisa formar cidadãos conscientes e críticos para o mundo.

De acordo com (LAJOLO, 2008, p.106).

É à literatura, como linguagem e como instituição, que se confiam os diferentes imaginários, as diferentes sensibilidades, valores e comportamentos através dos quais uma sociedade expressa e discute, simbolicamente, seus impasses, seus desejos, suas utopias. Por isso a literatura é importante no currículo escolar: o cidadão, para exercer plenamente sua cidadania, precisa se apossar da linguagem literária, alfabetizar-se nela, tornar-se seu usuário competente, mesmo que nunca vá escrever um livro.

O grande desafio da escola é mostrar a sua importância, considerando o desenvolvimento da leitura através de conscientização e estímulo aos alunos mesmo não tendo aulas presenciais, estimulando para a realização da leitura de forma prazerosa mostrando e despertando a vontade que cada indivíduo carrega em si sobre a importância de desenvolver o hábito de leitura mesmo fora da escola, e com isso sanar cada vez mais rápido as dificuldades que os alunos apresentam na organização de seus pensamentos.

Silva (2002, p. 26) relata:

Precisamos urgentemente superar essa visão à medida que no prazer da leitura, ou seja, na ampliação do campo do possível através do jogo criador existe conhecimento e conscientização. Em verdade, fruir o texto literário e crescer pessoalmente ou transformar-se politicamente são partes de um mesmo ato.

O que acontece na escola é que para esse tipo de leitura falta-lhe o senso crítico, diante da realidade e condições de fazerem escolhas pessoais para o seu futuro, o de sua comunidade e de seu país.

Entende-se que a escola consegue ampliar as possibilidades de práticas leitoras, se investir na sensibilização do aluno para com a leitura e a interpretação mesmo longe de sala. "Nessas condições remotas, mediação de leitura é saber segurar o celular, 
encontrar a melhor maneira de mostrar a imagem do livro em todos os detalhes, conversar sobre a história... então tudo isso é diferente e requer um aprendizado novo para o educador também” destaca Maria Alice Junqueira, coordenadora de projetos do CENPEC Educação, essas ações reverterão em benefícios no que diz respeito ao desempenho escolar, pois a leitura é o componente curricular que mobiliza diversos recursos cognitivos.

Para Neitzel (2006, p.99): “a entrega do sujeito à leitura despretensiosa de uma obra literária leva-o a um processo individual e subjetivo de observação, mediação, análise, julgamento, ponderação, articulação e construção de conceitos”. O livro é, pois, um instrumento libertador, pois é um símbolo mágico para o educando. Ele permite que o aluno desvende sensações e experiências vivas.

Se os benefícios da leitura já são muito conhecidos, eles se intensificam em uma situação adversa como a que estamos vivendo, em que o distanciamento social e o fechamento das escolas impactam diretamente na aprendizagem e no desenvolvimento de alunos de todo o país.

É importante que a escola ofereça um acervo literário bastante diversificado para seus alunos, com livros adequados a todas as idades. Os livros precisam conter fascínio, deslumbre, deve ter caráter imaginoso, com lendas, monstros, em forma de fábula, poemas e até mesmo quadrinhos. A beleza das imagens, traz mistério e emoção, faz com que as os adolescentes sintam vontade de completar a leitura, de saber o final da história. É a imaginação que permite o interesse de cada leitor pela leitura, partindo de leituras simples até as mais complexas.

Desse modo,(CARVALHO, 1989, p.21)afirma que,

A criança é criativa e precisa de matéria-prima sadia, e com beleza, para organizar seu "mundo mágico", seu universo possível, onde ela é dona absoluta: constrói e destrói. Constrói e cria, realizando tudo o que ela deseja. A imaginação bem motivada é uma fonte de libertação, com riqueza. É uma forma de conquista de liberdade, que produzirá bons frutos, como a terra agreste, que se aduba e enriquece, produz frutos sazonados.

A leitura é primordial para que o verdadeiro estudo e conhecimento aconteça, portanto, quem descobre prazer numa obra literária nunca mais para de ler. Quando chega ao fim de um livro, já está louco para abrir o próximo. E o papel da escola é fundamental nesse processo. São muitas as atividades que podem ser desenvolvidas 
com esse objetivo. É através da imaginação, do drama literário e da emoção sentida através da leitura de cada livro que os alunos ultrapassam seus limites e enfrentam dificuldades do dia-a-dia. Assim, as crianças conseguem entender as diferenças do mundo que a cercam.

Para (MEIRELES, 1984, p.77).

A natureza e intensidade dessas emoções podem repercutir na vida do pequeno leitor de maneira definitiva. Não apenas ele se lembrará, até a morte, desse primeiro encantamento, $[\ldots .$.$] muitas vezes, a repercussão tem resultados$ práticos: vocações que surgem, rumos de vida, determinações futuras.

De acordo com a educadora Maria José Nóbrega, promover um debate para discutir cenas ou situações presentes num livro que acaba de ser lido pela turma é uma prática importante e muitas vezes esquecida. Sabemos que a leitura proporciona um mundo de conhecimento e possibilidades para construírem e reconstruírem pensamentos e sentimentos. É importante que as propostas de atividades desencadeiam situações que permitam a investigação, o estabelecimento e o compartilhamento de ideias entre o grupo, deixando vir à tona seus cotidianos e suas impressões sobre o mundo.

A utilização de recursos para incentivar a prática de leitura fora da sala de aula é importantíssima, pois o aluno necessita desse incentivo e das práticas diariamente, assim será possível desenvolver o hábito e o prazer em praticar a leitura livremente e fora da escola sem cobrança do professor. Para Lajolo (2008) as experiências vividas, a linguagem com que se conta e se transfere o saber através da leitura pode influenciar na compreensão das crianças sobre conceitos e reconhecimento da linguagem utilizada nos textos literários. E ainda, é fundamental que as políticas de incentivo à leitura se desloquem da mera organização de feiras ou da criação de bibliotecas e salas de leitura. Ainda (LAJOLO, 2008, p.45) afirma que

[...] leitor e texto precisam participar de uma mesma esfera de cultura. O que estou chamando de esfera de cultura inclui a língua e privilegia os vários usos daquela língua que, no correr do tempo, foram constituindo a tradição literária da comunidade (à qual o leitor pertence) falante daquela língua (na qual o poema foi escrito).

Em um segundo momento, a missão de construir uma sociedade leitora fica a cargo das escolas. São elas que fornecem todo apoio e suporte material para que seus alunos se sintam à vontade com a leitura e que não usem-a somente em sala de aula. 
Cabe a elas fornecerem possibilidades para o encontro entre leitores e livros, pois como afirma Coelho, (2005, p.I08), e a partir de então, a tarefa fica dividida entre pais e professores, estimulando um futuro leitor, proficiente, crítico e ativo socialmente.

Segundo Silva (2002, p. 14):

Quem se dispõe a entrar numa sala de aula para ensinar tem que saber satisfatoriamente aquilo que ensina, tem que dominar os conteúdos e suas disciplinas, para orientar a leitura, o professor tem que ser leitor, com paixão por determinados textos ou autores e ódio por outros.

É do professor a tarefa de oferecer aos estudantes possibilidades de temas relacionados à leitura que seja do agrado da maioria de seus alunos. Na perspectiva de Brakling, (2003, p. 85), a finalidade principal das escolas, hoje, é formar leitores proficientes capazes de exercer a sua cidadania compreendendo criticamente o que leem. Para isso, o docente deve ter acesso a meios que o ajude na interação alunos $\mathrm{x}$ leitura e, além disso, o professor deve ter conhecimento da natureza da leitura indicada, ter noções de estratégias de leitura para os diferentes níveis de ensino e, o mais importante, o professor deve ser um leitor.

Sob o ponto de vista de Cavalcanti, (2008, p. 92), estimular o prazer pela leitura não é tarefa fácil, e essa responsabilidade não pode ficar restrita à escola. Os pais devem participar dessa construção do novo leitor, incentivando a leitura, tornando-a um momento de lazer e integração familiar.

O processo de incentivo à leitura deve ser estimulado, na criança, desde a infância, permitindo que ela, futuramente, seja uma leitora assídua, atuante e consciente do seu papel na sociedade.

Para Solé (1998, p. 62), o ensino da leitura deve garantir a interação significativa e funcional da criança com a língua escrita, como meio de construir os conhecimentos necessários para abordar as diferentes etapas da sua aprendizagem.

\section{METODOLOGIA}

A realização de uma pesquisa envolve aspectos importantes: o tipo de pesquisa, o percurso metodológico, os dados recolhidos e a discussão desses dados. Pensando assim, deu-se início a este estudo através de uma pesquisa bibliográfica cujos materiais relatam a importância de praticar a leitura. Assim, a pesquisa bibliográfica se 
constituiu, neste estudo, como procedimento indispensável para chegarmos mais perto dos conceitos e fundamentos que amparam nosso campo e objeto de estudo.

Para isso, Marconi e Lakatos (2006, p. 160), consideram que "a pesquisa bibliográfica é um apanhado geral sobre os principais trabalhos já realizados”. Isso justifica-se, pela sua relevância nas pesquisas sociais por concederem subsídios para a compreensão, análise e interpretação. Possuindo caráter qualitativo, conforme Minayo (2004, p. 2I-2) é aquela que "trabalha com o universo de significados, motivos, aspirações, crenças, valores e atitudes, que corresponde a um espaço mais profundo das relações”.

Já a pesquisa de campo foi utilizada para compreender com mais afinidade as questões que envolvem os sujeitos envolvidos, sobretudo, buscaram conhecer as práticas e as dificuldades da escola e dos professores como fonte de informação.

Como instrumento de coleta de dados foi utilizado o questionário, pois o mesmo de acordo com (FACHIN, 2003, p. 147).“consiste num elenco de questões que são apreciadas e submetidas a certo número de pessoas com o intuito de obter respostas para a coleta de informações" . No entanto, o questionário foi organizado com perguntas abertas, com o objetivo de conhecer melhor as ações desenvolvidas pela escola e pelos professores no incentivo à leitura realizada em casa, no período de pandemia.

A fim de preservar as identidades dos integrantes da pesquisa fez-se uso de pseudônimos, utilizando nomes de Professora A, B e C em substituição dos nomes dos participantes.

\section{RESULTADOS E DISCUSSÃO}

O desafio de pensar educação em tempos de pandemia faz-se ao pensar uma política pública de enfrentamento à desigualdade social, colocando assim o governo em ação. Segundo Cafardo (2020), os secretários de educação e entidades da sociedade civil, articulam-se para oferecer educação a distância para alunos de escolas públicas do País por meio de celulares (O Estadão, 2020).

A Escola Estadual Profo Valdir Monfredinho, representada neste trabalho pela Coordenação pedagógica e pelas professoras de Língua Portuguesa, as quais, atuam nessa escola pública e lecionam em turmas diferentes do ensino fundamental, foi 
escolhida para a realização desta pesquisa pela proximidade com as mesmas, e que por meio de uma posição ética, as professoras terão seus nomes mantidos em anonimato. Sendo assim, as docentes serão chamadas de Professoras A, B, e C.

Quando foram informadas sobre a pesquisa - a Direção da escola, a coordenação pedagógica e as professoras apresentaram interesse em responder ao questionário. Dessa forma, a primeira questão buscou saber quais as principais estratégias utilizadas por elas, para incentivar a leitura dos alunos em tempos de pandemia. E as respostas obtidas foram as seguintes:

Coordenação: $O$ trabalho de incentivo à leitura aos alunos da Escola Professor Valdir Monfredinho vem de longa data, em razão das características do nosso público, que em sua maioria pertencem a famílias de baixa renda, onde a leitura, muitas vezes acaba em segundo plano. Algumas estratégias que usamos na pandemia para incentivar a leitura: - Continuidade do projeto de leitura de forma remota; - Equipe de professoras disponíveis para atender o projeto; - Textos selecionados observando os objetivos a serem desenvolvidos por cada série. - Preparação de uma bibliografia adequada para a idade dos alunos e os conteúdos a serem trabalhados.

Professora A: - Realizando um trabalho de conscientização da importância dos gêneros textuais e apresentação de leitura de acordo com o interesse deles.

Professora B: - Neste período que estamos enfrentando está complicado trabalhar a questão da leitura em sala de aula modo remoto, porém, um meio que encontrei de estimular a leitura é enviando vários textos aos alunos e na sala online, escolher alguém para ler, geralmente é por sorteio dos que estão online, mas encontramos o desinteresse muito grande dos alunos, essa foi a forma que achei mais viável, também incentivo a lerem obras de alguns autores, mas são poucos os que embarcam nos desafios.

Professora C: Procuro trabalhar com gêneros textuais mais curtos, como contos, fábulas, crônicas, quando possível, envio a versão em áudio ou vídeo para despertar maior interesse pelo texto.

A literatura escolhida deve ser flexível, capaz de produzir deslumbramento e curiosidade, autonomia e criticidade, conhecimento e aprendizado. Suas falas nos ajudam a compreender que, a escola deve promover e promove dentro de sua 
capacidade, práticas que facilitam a desenvoltura da leitura, à aprendizagem, a criatividade, a expressão, a socialização, através de uma conduta ética de respeito e apoio recíprocos.

Segundo Sopelsa (200o, p.34) cita que

Desde o nascimento até a morte, o homem sofre influências das pessoas, da sociedade, do mundo, e reage a estas influências de acordo com as raízes que lhe foram impressas, ao longo de sua existência, pelas suas vivências e sentimentos.

É no ambiente escolar, principalmente em comunidades vulneráveis onde se encontra a escola pesquisada, que a escola assume funções que vão além do ensino, onde se dá a socialização, lá também são construídos laços afetivos com colegas e professores que poderão ocupar papel importantíssimo na vida de uma criança, principalmente se esta passou por adversidades

Para Ferreira e Marturano (2002, p.39) “crianças provenientes de famílias que vivem com dificuldades econômicas e habitam em comunidades vulneráveis, tendem a apresentar mais problemas de desempenho escolar e de comportamento".

$\mathrm{Na}$ escola as crianças recebem livros de tamanhos e formas variadas, com assuntos e contextos diferentes, mas não é isso que vai fazer a crianças perder ou adquirir o hábito de ler esse livro, e sim, a importância que a escola dará a esse significativo recurso, esse mérito é perceptível nessa escola quando a mesma dá continuidade à projetos sobre leitura disponibilizando professores específicos para atenderem e motivarem os alunos a praticarem a leitura, mesmo os alunos não estando presente fisicamente na escola.

Essas medidas realizadas têm o intuito de motivar os alunos a continuarem o processo de desenvolvimento da leitura, mesmo que a distância, mas com o objetivo de colaborar para que estes sujeitos se mantenham conectados com a escola e com o ensino-aprendizagem ofertado. De acordo com Lajolo (1996), a leitura é uma estratégia eficaz no processo de ensino-aprendizagem, sendo praticada pelos alunos de diversas formas e métodos.

Já a segunda pergunta do questionário buscou saber como a escola, através da coordenação e as professoras, através de suas aulas remotas, estimulam os alunos a 
desenvolver o hábito de ler durante a pandemia. E sobre isto a coordenação e as professoras investigadas afirmaram:

Coordenação: $\mathrm{Na}$ pandemia não deixamos de atender esse público dentro de novas adequações. As ações passaram a ser online, organizadas pelo grupo de professores da Biblioteca que conduziram o projeto. Os alunos eram convidados a ler através de videoconferência, integrando-se de forma remota com a professora de leitura.

Professora A: - Propondo exposição da leitura realizada ,durante a aula on-line. Eles amam!

Professora B: - Escolho textos curtos e envio para eles por whatsapp ou classroom para estimular a leitura.

Professora C: Com a necessidade constante dos meios digitais durante a pandemia, procuro sugerir leituras que tenham a versão em PDF onde o aluno pode baixar em seu computador ou celular para fazer a leitura no próprio aparelho.

A revolução tecnológica que o mundo vive atualmente, embora traga novas e valiosas configurações para a educação, também impõe alguns desafios, especialmente aos mais jovens, no que tange ao processo de leitura nesse período de pandemia.

Através das respostas analisadas foi possível perceber que esses profissionais estão utilizando diversas ferramentas tecnológicas para que os alunos estejam bem assistidos. A revolução tecnológica mundial, atualmente, embora traga novas e valiosas configurações à educação, também impõe alguns desafios, especialmente aos mais jovens, quanto ao processo da leitura, mas a utilização desses recursos pode ser fundamental. Quando o professor consegue em sua classe desenvolver uma esfera de confiança e amizade o trabalho torna-se mais fácil e o sucesso dos alunos é mais provável.

Segundo Coll (1994, p.103):

Os processos escolares de ensino/aprendizagem são, em essência, processos interativos com três vértices: o aluno que está levando a cabo uma aprendizagem; o objeto ou objetos de conhecimento que constituem o conteúdo da aprendizagem; e o professor que age, isto é, que ensina, com a finalidade de favorecer a aprendizagem dos alunos. 
O professor utilizando-se de seus recursos e de sua metodologia, deve agir como mediador entre o objeto de conhecimento e a aprendizagem, para tornar as experiências vivenciadas pelas crianças significativas.

As Tecnologias Digitais se tornam um reforço de suma importância na educação atual, pois apresenta como funções instruir os alunos, colaborar com a metodologia dos docentes e enriquecer o trabalho dos gestores, entre outras contribuições. Os professores, nesse momento, precisaram aprender novas formas de ensinar e claro, tiveram que mudar a forma de ministrar suas aulas, sendo de grande significância o uso de recursos tecnológicos digitais, que auxiliam também os alunos dando todo o suporte necessário para que eles compreendam os conteúdos com mais clareza e esclareça suas dúvidas.

Sendo assim, Garcia et al. (2020, p.09) ressaltam que:

Aprender é uma atitude cuja competência precisa ser desenvolvida. A pró atividade, a inventividade, a responsabilidade e o compromisso são condutas que precisam ser construídas e incentivadas. No ensino remoto, o estudante terá de ser gradativo e continuamente incentivado e promovido para a aprendizagem.

O distanciamento social deixou o professor mais distante dos alunos, mas as tecnologias estão servindo de elo para reaproximar o educador e o educando, para que com isso sejam alcançados resultados positivos.

No entanto, a terceira pergunta buscou saber quais as principais dificuldades enfrentadas pela coordenação e pelas professoras referentes à prática de leitura durante o período de pandemia. E sobre essa pergunta, as pesquisadas responderam:

- Coordenação: Estabelecer contato com os alunos que não dispunham de internet;

- Cumprimento do horário estabelecido para a leitura através de videoconferência;

- Professora A: O difícil acesso à Internet e à biblioteca.

- Professora B: São muitas dificuldades, o retorno é pequeno em relação a todos, a forma de aula remota a meu ver parece que deixa os alunos desestimulados, sinto que não tem compromissos com a questão do estudo em geral. 
- Professora C: A principal dificuldade é justamente a distância entre os alunos e eu. O fato de não conseguir fazer aquela roda de leitura em voz audível e na hora já poder corrigir questões como, respeito a pontuação no texto, entoação, vocabulário etc.

A pandemia acentuou a diferença entre aqueles que tinham mais dificuldades de aprender; exigiu um novo educador, que precisou se reinventar, teve que se adaptar às novas tecnologias, novas metodologias, transformando-se. Foi preciso buscar meios para adaptar e amenizar as barreiras que impedem os alunos de se envolverem totalmente com as oportunidades de aprendizagem remota, tais como: necessidades educacionais especiais do aluno, a falta de conhecimento dos pais do conteúdo pedagógico, necessidade de melhor comunicação com o professor, falta de acesso às tecnologias digitais e qualidade da internet.

As novas Tecnologias estão trazendo vários benefícios para a sociedade, ocasionando uma maior interação entre as pessoas e já fazem parte da realidade de muitos cidadãos. Porém, infelizmente não são todos que conseguem ter acesso a esses recursos tecnológicos e acabam não podendo usufruir de suas vantagens (VILAÇA; ARAÚJO, 2016)

Nesse momento de distanciamento, a tecnologia se torna uma oportunidade de contribuir positivamente tanto no ensino remoto, quanto aos processos de aprendizagem, proporcionando novas formas de ensinar e, principalmente, de aprender.

Os desafios apresentados, que relatam os desafios enfrentados por professores e alunos, podem também ser considerados como uma proposta desafiadora e estimulante, e não como dificuldade, pois, pensando na capacidade de superá-las, tornam-se habilidades, podendo ser classificadas como competências, que são extremamente necessárias para os dias atuais, com as quais a sociedade precisa desenvolver para se adaptar a uma realidade em que as tecnologias, o mundo digital e as novas formas de relações humanas estão cada vez evidentes e naturais.

E por último, a quarta pergunta buscou saber o que poderia ser feito para ampliar as possibilidades de incentivar o aluno a inserir a leitura em sua rotina diária no período de pandemia. E sobre essa pergunta, obteve as seguintes sugestões:

- Coordenação: .Disponibilizar internet para todos os alunos. 
- Professora A: Possibilitar o acesso à Internet e bibliotecas.

- Professora B: Tem muitas formas de estimular a leitura, os professores correm atrás, buscam meios, porém, creio que o desânimo vem por parte dos alunos mesmo, vejo por experiência própria, foi criado uma sala para os alunos a sala do saber, nós como professores, incentivamos a acessarem a página, uma página rica em conteúdo, porém a procura foi pequena. Mas um meio que encontro é não desanimar nunca e fazer a minha parte, enviando textos curtos, dando notas.

- Professora C: É necessário fazer com que o aluno entenda que a leitura é entretenimento, prazer, experiência, emoção... Em meio a uma pandemia onde tivemos que nos manter dentro de nossas casas, a leitura é o que nos torna capazes de nos fazer viajar para muitos lugares por meio da imaginação.

O ensino tem sofrido muitas mudanças; no entanto, há distanciamento muito grande entre o fomentado e o aplicado, entre o ofertado e o consumido. Seja por questões das diferenças socioeconômicas da sociedade brasileira, seja até pela infraestrutura precária, pela inacessibilidade, a nova forma de aprender e ensinar segrega muita gente.

Assim tem-se a possibilidade de associar o aprendizado às questões sociais e à realidade em que o (a) aluno (a) se encontra por meio de uma prática pedagógica em que (FAZENDA, 1992, p. 56), afirma:

[...] não se ensina, nem se aprende, apenas vive-se, exerce-se... Todo o indivíduo engajado nesse processo será não o aprendiz, mas, na medida em que familiarizar-se com as técnicas e quesitos básicos, o criador de novas estruturas, novos conteúdos, será o motor de transformação Em tempos de pandemia, a criação de ambientes virtuais destinados a práticas de comunicação, leitura, escrita e aprendizado transcende a pedagogia tal como foi pensada tradicionalmente, pois a falta de domínio dos alunos em relação às TICs; as dificuldades de acesso à internet e da interação pedagógica mediada pelas tecnologias. No caso desta pesquisa, a transição do ambiente presencial para o ambiente virtual ocasionou a resistência ao novo pelos estudantes não habituados às TICs, a timidez dos alunos para se expressarem, bem como as dificuldades financeiras e de acesso à Internet.

Vimos que o processo educacional remoto deve ser viabilizado, trazendo, além da conexão, a percepção do quanto o mundo tecnológico tem a contribuir em todo 
método de ensino-aprendizagem, ao qual Fantin (201, p. 28) ressalta sobre a importância das tecnologias digitais para a sociedade, abrindo espaço para a reflexão sobre o papel que as mídias têm desempenhado na contemporaneidade e na formação dos sujeitos, em destaque aqui, para os estudantes, futuros profissionais.

Por esse motivo, as políticas públicas devem propiciar ao cidadão uma melhoria de vida na área educacional, social e cultural, promovendo a transformação da realidade do povo (FURTADO, 2oII, p. 2).

A escola não pode ser refúgio da família, colocando toda a responsabilidade da educação para essas instituições, na verdade a escola apenas complementa o ensino dado pelos pais.

Jardim (2006, p. 43) enfatiza que:

A responsabilidade de educar não pode ser só atribuída à família ou à escola, pois se a família atua de forma profunda e durante mais tempo, a escola oferece condiç̃̃es especiais para influir sobre o educando, pela formação especializada de seus elementos.

A adaptação de alunos, professores e instituições para as aulas remotas trouxe uma evolução na concepção de educação que com certeza mudará para sempre o conceito do que é ensino, além de forçar a comunidade escolar a aprender novas competências, conhecer formatos de ensino, interagir através de aplicativos que se transformam em verdadeiras salas de aula.

\section{CONSIDERAÇÕES FINAIS}

Este estudo possibilitou uma discussão sobre os desafios da educação em tempos de pandemia e a importância da ação da escola, por parte da coordenação e dos docentes frente à realidade imposta pela sociedade contemporânea. Observou-se a elevada importância do conhecimento e das habilidades com a tecnologia, assim como de outras características cognitivas que formam as competências pessoais necessárias.

Ainda estamos todos vivenciando a prática do ensino remoto, com o retorno das aulas presenciais sendo feito aos poucos, com cautela, e realizando discussões sobre a volta total das aulas presenciais em um novo normal. Ressaltamos que, embora a pedagogia enquanto ciência reúna as teorias sobre o ensino e a educação, define métodos que garantem a adequação ou adaptação frente ao ensino e a aprendizagem, é sem 
dúvida o professor o ser central dessa prática, o indivíduo que torna possível fazer o que ainda não se fez e experimenta fazer sem saber o que fazer, mas de maneira responsável, aprendendo a fazer uso dos saberes e construindo novos saberes.

$\mathrm{Na}$ atualidade, a sala de aula é virtual, às vezes inexistente para quem não tem um celular ou não dispõe de internet e conta apenas com o material impresso organizado pelos professores, ou acontece numa chamada de áudio, de vídeo ou através de mensagem pelo WhatsApp, mas é no cuidado da elaboração da aula virtual ou do material impresso que se percebe a autonomia e a esperança do professore de toda equipe pedagógica e administrativa das escolas em tornar possível o aprendizado num contexto de isolamento social.

Com a paralisação das aulas presenciais os (as) estudantes precisaram se adaptar a essa nova realidade, reorganizando a sua rotina de estudo diário em casa e assumindo agora uma postura mais independente sobre o processo de aprendizagem. Nunca foi tão importante criar hábito de ler, tanto para estudar, quanto para vencer a ociosidade causada pelo distanciamento social. A leitura é uma ferramenta que transporta o aluno a diversos conhecimentos que podem ser contextualizados.

Vale destacar que a escola conectada não é aquela que tem apenas a conexão com a internet. É, antes de tudo, aquela que sabe utilizar a tecnologia nas práticas pedagógicas, que desenvolve competências digitais em toda a sua equipe, que tem um conjunto de materiais digitais alinhados e já pré-selecionados ao seu currículo e que dispõe de um número suficiente de equipamentos e conectividade para professores (as) e alunos (as) poderem utilizar nas atividades em sala de aula.

Nessa perspectiva, buscamos adequar as atividades ao novo modelo de ensino de caráter emergencial, remoto e temporário, utilizando os recursos tecnológicos como ferramentas para estimular a leitura e a escrita, permitindo aos alunos aliar tecnologia e reflexão de forma prática. Nosso foco principal é darmos continuidade ao processo de ensino-aprendizagem, levando aos (às) nossos (as) alunos (as) propostas pedagógicas que favoreçam o estímulo pela leitura diária, de forma prazerosa e autônoma.

O que se espera é que as novas dimensões da tecnologia na educação, amparadas pelas políticas públicas do Estado em seus diferentes níveis e esferas (federal, estadual, municipal), determinadas pelas demandas socioculturais e econômicas, assumam um 
papel colaborativo e propulsor para a difusão do conhecimento, para a socialização do saber.

Analisamos algumas estratégias que os professores aprenderam e que estão usando atualmente para facilitar suas rotinas e a compreensão das crianças diante do contexto das aulas remotas. Vimos que é necessário que os professores e os alunos tenham uma rotina programada para os estudos.

Diante do exposto é indispensável lembrar que a tecnologia tem sido uma aliada e vilã ao mesmo tempo dos professores nesse momento, visto que, é através dela que se pode alcançar mais crianças e obter mais ferramentas de trabalho, como também, os professores precisam, de maneira abrupta aprender a lidar diversos tipos e meio de comunicação que nem conheciam para ministrar suas aulas.

Acreditamos que os resultados aqui apresentados nos dão pistas interessantes sobre a realidade do trabalho docente e suas transformações no contexto do ensino remoto com ênfase no desenvolvimento da leitura

Nota-se que profundas mudanças aconteceram no decorrer do tempo, as quais trouxeram relevantes transformações que impactaram fortemente a vida das pessoas, das instituições e das organizações. Nos encontramos numa sociedade que está em constante revolução tecnológica, devendo ser considerados os impactos que geram mudanças em todas as áreas que envolvem a sociedade como um todo, no modo de vida das pessoas, na política, dentre outras questões que requerem a adaptação de todos.

E, finalmente, a dura certeza do retrocesso no ensino e aprendizagem, em especial por não termos o controle de todas as variáveis favoráveis, a forma como nos distanciamos e como os estudantes estão lidando com a resolução das atividades, os conflitos e os dramas familiares, o que poderá agravar a evasão e o abandono, problemas que a cada ano estávamos conseguindo identificar e corrigir, minimizando os nossos índices

Por fim, o momento ensina que os professores precisam motivar e fomentar estratégias para que os alunos aprendam a aprender, visto que o atual momento da educação pede mais autonomia no aprendizado.

\section{REFERÊNCIAS BIBLIOGRÁFICAS}


CAFARDO, Renata. Educação a distância para alunos de escolas públicas deve ser feita por meio de celulares. Disponível em: <https://educacao.estadao.com.br/noticias/geral,educacao-a-distancia-para-alunos-deescolas-publicas-deve-ser-feita-por-meio-de-celulares,70oo> Acesso em: 03 maio 2020.

CARVALHO, Bárbara Vasconcelos. A literatura infantil - Visão Histórica e Crítica 6 Ed. São Paulo: Global. (1989).

COLL, César. Aprendizagem Escolar e Construção do Conhecimento. Porto Alegre: Artmed, 1994 .

DIAS, Flávia Brito; QUADROS, Deisily. A literatura e a escola: tensões e possibilidades. In: CONGRESSO INTERNACIONAL DE LITERATURA INFANTIL E JUVENIL, 2015.

FACHIN, Odília. Fundamentos de metodologia. 4. ed. São Paulo: Saraiva, 2003.

FAZENDA, I. C. A Integração e interdisciplinaridade no ensino brasileiro: efetividade ou ideologia? São Paulo: Loyola, 1992.

GARCIA, T. C. M. et al. Ensino remoto emergencial: proposta de design para organização de aulas.Caderno de Ensino Mediado por TIC. Natal, 2020

FERREIRA, Marlene de Cássia Trivellato; MARTURANO, Edna Maria. Ambiente familiar e os problemas de comportamento apresentados por crianças com baixo desempenho escolar. Psicologia: Reflexão e Crítica, Porto Alegre, v. 15, n. I, p. 35-44, 2002.

JARDIM, Ana Paula. Relação entre Família Escola: proposta de Ação no Processo Ensino - Aprendizagem. Disponível em: 
http://tede.unoeste.br/tede/tde_arquivos/I/TDE-2006-04-12TI21858Z-

I2/Publico/DISSERTACAO_EDUCACAO_Ana\%2oPaula\%2o Jardim_\%2otexto.pdf.

LAJOLO, Marisa. Do mundo da leitura para a leitura do mundo. $6^{\underline{a}}$ ed. $13^{\underline{a}}$ impressão. São Paulo: Editora Ática. (2008).

A formação do leitor no Brasil. São Paulo: Ática, 1996.

LIMA, Cibele Bastos Mendonça; FREITAS, Dercília Maria de; GIAROLA, Juliana Bizarro Ferraz; PAULA, Nancy Cherigath Romero de; ROCHA, Gustavo Gomes Siqueira da. Práticas de leitura em tempos de pandemia: relato de experiência do clube de leitores Te Indico. Revista Educação Pública, v. 20, no 48, I5 de dezembro de 2020

MARCONI, M. de A.; LAKATOS, E. M. Metodologia do Trabalho Científico. $5^{\circ}$ ed.rev. ampl. São Paulo: Atlas, 2006.

MEIRELES, Cecília. Problemas da literatura infantil. Rio de Janeiro: Nova Fronteira, 1984 .

MINAYO, M. C. S. (Org.). Pesquisa social: teoria, método e criatividade. Petrópolis: Vozes, 2004.

NEITZEL, Adair de Aguiar. Sensibilização poética: educar para fruição estética. In: SCHLINDWEIN, L. M.; SIRGADO, A. P. (Org.). Estética e pesquisa: formação de professores. Itajaí: Univali, Maria do Cais, 2006.

SILVA, Ezequiel Theodoro da. A produção da leitura na escola: Pesquisas x Propostas. 2. Ed. São Paulo: Editora Ática, 2002.

SOLÉ, Isabel. Estratégias de Leitura. 6. ed. Porto Alegre:ArtMed,I998.

SOPELSA, Ortelina. Dificuldades de Aprendizagem: respostas em um atelier pedagógico. 2 ed. Porto Alegre: Edipucrs, 2000. 
VILAÇA, M. L. C.; ARAÚJO, E. V. Tecnologia, sociedade e educação na era digital /livro eletrônico. UNIGRANRIO, Duque de Caxias, 2016

https://www.construirnoticias.com.br/ler-e-compreender-eis-a-questao/ acessado em 27/09/2021. 